\title{
Voltando a página do tempo: drama e folhetim nos portais do jornalismo on-line
}

\author{
Back to the timeline pages: drama and novels in the online journalism
}

\author{
Gabriela Pavanato Sardinha ${ }^{l}$ \\ (gabrielapavanato@gmail.com) \\ http://dx.doi.org/10.5216/cei.v16i2.26981
}

\section{Resumo}

O objetivo desse trabalho é analisar o jornalismo em sua ancoragem na internet. O ambiente virtual rompeu dificuldades históricas de produção, no entanto, a análise do cotidiano mostra que esse não tem sido um campo de novas linguagens, mas da possibilidade de registrar notícias com uma rapidez sem precedentes. A estrutura de mosaico identificada nos jornais impressos por Marshall McLuhan aplica-se com desenvoltura ao jornalismo on-line. O objeto de estudo são portais de conteúdo jornalístico, percebidos como sistemas compostos por um conjunto de manchetes, formando um campo simbólicoque, muitas vezes, irá dispensar a visita do leitor ao conteúdo das matérias. A partir desse conjunto, investigamos se há um pressuposto de que determinados tipos de notícias têm sido estabilizadores desses sistemas, dada a natureza caótica criada pela quantidade e variedade de assuntos expostos simultaneamente. Para isso, nos amparamos nos estudos de Roland Barthes sobre a estrutura dos "fait divers", identificando uma categoria de notícias espantosas ou ficcionais que funcionariam como atenuantes no espaço fragmentado. Tal percepção indica que é possível que o jornalismo on-line ainda não se diferencie muito dos primórdios do jornalismo de massa, iniciado nos anos de 1830. A trama cotidiana permanece como um tecido trançado entre realidade e ficção e os avanços tecnológicos podem ser relegados ao plano do suporte, porque o jornalismo, em sua ancoragem na internet, dá ares de apenas simular novos recursos, já que neste aspecto, ressurge com a mesma roupagem daquele praticado há mais de 200 anos.

Palavras-chave: Jornalismo. Jornalismo on-line. Fait divers. Mosaico.

\begin{abstract}
The aim of this work is to analyze the journalism in its anchorage on the internet. The historical difficulties of productions do not exist in the virtual environment; however, the daily analysis shows us that there is not a field of new languages, but the possibility of proffer news with unprecedented speed. The mosaic structure identified by Marshall McLuhan in the newspapers would be applies to online journalism. The object of study are sites of journalistic content, perceived as systems composed like a set of headlines, forming a symbolic field that offers to the reader's the possibility of not visit the content of the complete news. From this set, we investigated whether there is an assumption that certain types of news stabilize these systems, given the chaotic nature created by the quantity and variety of themes exposed simultaneously. For this, we have been used the Roland Barthes' studies on the structure of the "fait divers", to identifying a category of amazing or fictional stories that soften the fragmented space. This perception indicates that perhaps some aspects of online journalism are like the early days of the newspapers in the 1830s. The web remains as a braided fabric between reality and fiction and the technological advances could be relegated to the plane of support, because the journalism in its anchorage on the internet, seems just simulate new features, since this aspect resurfaces with the same clothes of over 200 years.
\end{abstract}

Keywords: Journalism. Online journalism. Fait divers. Mosaic.

\footnotetext{
${ }^{1}$ Doutoranda em Comunicação e Semiótica (Bolsa CAPES), pela PUC/SP, possui mestrado em Comunicação e Semiótica pela mesma instituição e graduação em Jornalismo pela Pontifícia Universidade Católica de Campinas. Atualmente é Diretora de Comunicação e Turismo da Universidade Nove de Julho - UNINOVE, tendo sido coordenadora dos cursos de Jornalismo e de PósGraduação em Comunicação e Mídia e Comunicação Empresarial e Institucional na mesma Universidade. Professora universitária das disciplinas Comunicação e Linguagens e Análise do Discurso em Comunicação.
}

Comun \& Info, v. 16, n. 2, p. 136-148, jul./dez. 2013 


\section{Introdução}

primeira página de um jornal figura como destacado espaço simbólico em que os
assuntos enunciados ganham realce no imaginário social e acabam por interferir na
composição da realidade cotidiana. Dentre suas características, está a marcação do tempo, representado pela data, como um princípio organizativo, que elenca as notícias daquele dia. É nesse sentido que o jornal opera uma crença social direcionando discussões acerca dos "temas mais importantes”. Em 1964, Marshall McLuhan, dedicado aos estudos dos meios de comunicação, acabou por identificar uma estrutura recorrente nas páginas de jornal a qual chamou de mosaico, por ser composta de vários fragmentos. Para ele, esse formatodeterminou a própria identidade do jornal: "Mesmo antes da aceleração produzida pelo telégrafo, o jornal do século XIX já havia desenvolvido bastante a sua forma de mosaico", dizia o autor (McLUHAN, 1998, p. 232).

Inicialmente, os jornais esperavam que as notícias chegassem a eles, proclamando sua periodicidade de acordo com a demanda. Foi apenas em seu processo histórico, quando começaram a perceber que as notícias precisavam não apenas de registro, mas também serem "descobertas", é que se consagrou que apenas o que vai para o jornal é notícia, despertando, então, o referido elenco de temas mais relevantes para a sociedade.

\footnotetext{
Bem antes que o mundo das grandes empresas e dos altos negócios percebesse que suas operações formavam uma imagem fictícia a ser meticulosamente tatuada na pele do público, a imprensa já criara a imagem da comunidade como série de ações em processo unificadas por datas. À parte seu uso vernacular, a data é o único princípio organizativo da imagem jornalística da comunidade. Elimine-se a data e o jornal de um dia se torna igual ao do dia seguinte. Ler um jornal de uma semana atrás sem perceber que não é de hoje é um experiência desconcertante. (McLUHAN, 1998, p. 240).
}

A disposição de vários assuntos, como pequenos fragmentos - especialmente considerandose a primeira página - reflete a própria sociedade que enuncia, com seus recortes e rupturas, fazendo abordagens superficiais acerca de interesses coletivos e deixando de lados as questões particularizadas. McLuhan (1998, p. 241) destacou que: "Se prestarmos a devida atenção ao fato de que a imprensa é um mosaico, uma espécie de organização participante e um mundo do tipo 'faça você mesmo', podemos ver por que ela é tão necessária a um governo democrático”. Um governo democrático precisa instalar um significante de comunicação com seus eleitores, mesmo que apenas 
simule um processo de transparência. O jornal organizado como um mosaico atende a esse propósito, pois parece oferecer à comunidade informações sobre todos os assuntos que precisam ser de conhecimento público. Revestir a notícia de valor é saber em qual parte do mosaico deve ser apresentada, para chamar a atenção dos leitores e organizá-la em torno da prioridade de leitura. Portanto, a relação entre o tempo - a data de publicação do jornal - e o espaço - o local onde uma notícia será exibida no mosaico, transformam-se em um significante com um sentido fechado, inicialmente, por essa composição. Narrativas muito semelhantes, cotidianamente, como reparou McLuhan, só entusiasmam o leitor, porque são recobertas com uma nova data, todos os dias. Se o tempo é uma marca valorativa, o espaço que o acomoda é um aspecto distintivo.

A era virtual enfatiza, tanto quanto os meios impressos, o tempo, referenciando-o ao imediatismo na divulgação de notícias. Para o filósofo Christoph Türcke, a era virtual é de irradiação midiática:

É apenas agora, no momento de sua ausência, que se mostra o quanto é real aquilo que pretensamente seria somente uma realidade virtual, e o quanto se fez pálido e insosso o aqui e agora. Ela adquire a aparência de uma força vital coletiva, cuja ausência não pode ser suportada. E até onde vai essa força fica evidente pelo que começa até mesmo a redefinir o que seriam a vida e morte. Quem não emite não é, ou seja, ele pode estar tão vivo quanto possível, ter os melhores parâmetros sanguíneos e o melhor caráter; midiaticamente está morto. E a ilusão midiática, que o faz parecer morto, é irradiada, por sua vez, como se representasse a vida plena, embora seja feita de pixels mortos. (TÜRCKE, 2011, p. 46).

Esse novo ambiente soltou as amarras inerentes às práticas jornalísticas, direcionando promissoras discussões para uma nova linguagem. Abriu-se a oportunidade de se repensar o próprio conceito de reportar, uma vez que o espaço não é mais limitado pela finitude das páginas impressas ou pelo tempo de produção, acenando para uma perspectiva mais coletiva e democrática, o que poderia derrubar a restritiva visão de mosaico aventada por McLuhan. No entanto, a análise dos mosaicos que se constroem cotidianamente mostra que esse não tem sido um campo de outras linguagens, mas da convergência das linguagens de mídias tradicionais, com o diferencial de registrar e entregar a notícia com uma rapidez sem precedentes.

Para Bernardo Kucinski (2004, p. 77) o jornalismo on-line não explica o que mudou ou não na prática jornalística em função da internet. $\mathrm{O}$ autor afirma que esse jornalismo não se distingue do serviço tradicional de agências de notícias sob o aspecto da atualidade da informação, mas que definiu-se um novo ritmo de abastecimento de notícias, no qual os fatos vão sendo narrados continuamente em textos curtos e pouco acabados, à medida que vão acontecendo. No entanto, com os avanços tecnológicos, pode-se dizer que as disposições sobre espaço e tempo, marcas distintivas 
do jornalismo, foram alteradas. De acordo com Kovach e Rosenstiel (2003, p. 206),embora a nova tecnologia tenha dado maior vigor a um fórum para a crítica e o comentário público, também aumentou seu poder de distorção. Com a internet, a capacidade de informar e tornar os fatos conhecidos de um número imprevisível de pessoas rompeu as dificuldades logísticas de publicação. Ainda mais insidiosa, é a questão do tempo, cada vez mais diminuto entre o acontecimento e sua veiculação. Some-se a isso a facilidade do cidadão em informar ou questionar um fato devido à acessibilidade aos meios tecnológicos, tornando-se um sujeito da imprensa em qualquer instante e lugar. Mesmo assim, a sociedade se reorganiza para reservar ao jornalismo, a credibilidade nos processos de informar. Esse, por sua vez, utiliza-se dos relatos e testemunhos disponíveis inserindoos no processo da notícia.

À primeira vista, o que distingue um jornal de outro é um perfil próprio, que lhe confere identidadepelo arranjoque possui de notícias, como um verdadeiro mosaico, em que as partes serão feitas de editorias que se tornam marcas delimitativas invisíveis ao simular núcleos do sistema jornalístico. De forma perceptível, o novo sistema jornalístico exalta a estrutura de mosaico ou da fragmentação, aplicando-se com nova desenvoltura,o que foi detectado nos jornais impressos há cerca de meio século, ao jornalismo on-line. A transposição do conceito da "primeira página" (front page), dos jornais impressos para os portais de notícias, parece adequada ainda que o tempo de registro esteja alterado. É a ideia de "tempo real" que faz com que esse jornalismo crie um novo espaço simbólico, ainda entrelaçandosignos que simulam a realidade e a ficção, em uma trama que preserva a forma de enunciar os conteúdos.

Uma vez instaurados, a assinatura de cada um dos núcleosdependerá da perspectiva adotada para a narrativa. Em meio a essa composição, ancorado no espaço simbólico, há umestiloque não depende da marca valorativa do cotidiano, mas que faz da data um índice de sua produção, mesclando-se ao jornalismo desde o início de sua história. É o caso dos folhetins, um gênero literário, produzido para ser veiculado em partes ou capítulos e que está presente nos rodapés dos jornais desde os tempos mais remotos de sua massificação.A pesquisadora Marlyse Meyer (2005, p.30) explica que o folhetim e o jornal estão estreitamente ligados: o primeiro foi inventado pelo jornal e para o jornal:

O feuilleton-roman, como era chamado a princípio, acabou sendo fator condicionante da vida do mesmo. Nasceu na França, na década de 1830, concebido por Émile de Girandin, que percebeu, na época de consolidação da burguesia, o interesse em democratizar o jornal, a chamada grande presse, e não mais privilegiar só os que podiam pagar por caras assinaturas. Para aumentar o público leitor havia, pois, que barateá-lo - o que se conseguiu também mediante a utilização da publicidade, de origem inglesa - e arejar-lhe a matéria,

Comun \& Info, v. 16, n. 2, p. 136-148, jul./dez. 2013 
tornando-o mais acessível. Havia já, desde o começo do século, o feuilleton, ou rodapé, tradicionalmente, de tom e assunto mais leves que o resto do jornal, muito cercado pela censura. Podia ser dramático, crítico, tornando-se cada vez mais recreativo. $\mathrm{O}$ folhetim vai ser completado com a rubrica "variedade", que é a cunha por onde penetra a ficção, na forma de contos e novela curtas. (MEYER, 2005, p. 30)

O folhetimtoma parte no jornal operando um fazer diferente junto aosleitores, resgatando-os da simulação do real, instaurado pelas notícias do dia revestidas pela marca do tempo presente. Instalar a ficção, no mesmo espaço simbólico, compõe uma interessante conexão entre signos que simulam o real e o não-real, já que o tempo presentificado não é uma exigência de credibilidade para a ficção.No entanto, notícias e ficção são movidas pela expectativa de continuidade que são capazes de gerar. Meyer explica que o folhetim detém um ar de "suspense" criado por cortes que se lançam à continuidade "do capítulo seguinte". Além da técnica do suspense, o ritmo rápido e os temas românticos lhe conferem identidade: o herói vingador ou purificador, a jovem deflorada e pura, os terríveis homens do mal, os grandes mitos modernos da cidade devoradora, a História e as histórias fabulosas. As notícias, não ficcionais, também imprimem um ritmo rápido de leitura e possuem temas que as particularizam (política, polícia, economia, cultura), porém ancorados nos fatos do dia a dia.

\section{Os mitos da imprensa}

Além das categorias do tempo e do espaço, a estrutura que organiza os significantes, nojornalismoon-lineé similar à estrutura que organizaos meios impressos. O sentido fechado gerado pela forma como essa vitrine acidental do cotidiano é constituída, espelha um tipo de resumo dos fenômenos sociais que surgem revestidos pelos temas de reportagens evidenciados, há várias décadas, em semanários, jornais e revistas.

Roland Barthes, entre 1954 e 1956, denunciou a imprensa como uma grande criadora de mitos. Segundo ele, havia um sentimento de impaciência frente ao "natural" com que a imprensa mascarava continuamente uma realidade "que por ser aquela que vivemos, não deixa de ser por isso perfeitamente histórica" (BARTHES, 2010, p. 242). O mito, afirmava, é uma linguagem, um sistema de comunicação, uma mensagem. Assim, os jornais ultra-significam os fatos. O conceito barthesiano mostra que aquilo que permite ao leitor consumir o mito inocentemente é o fato de ele vê-lo como um sistema indutivo, uma espécie de processo causal, no qual o significante e o significado mantêm relações naturais: 
Pode-se exprimir essa confusão de outro modo: todo sistema semiológico é um sistema de valores; ora, o consumidor do mito considera a significação como um sistema de fatos: o mito é lido como um sistema factual, ao passo que é apenas um sistema semiológico. (BARTHES, 2010, p. 223).

Para trazer o conceito de mito na atualidade, como um discurso, uma mensagem e, portanto, perfeitamente identificável nos produtos que a imprensa recobre com o discurso jornalístico, Barthes preparou uma série de ensaios com temas retirados dos jornais e revistas, além de comentar os costumes da sociedade francesa. Uma de suas principais contribuições foi perceber que os discursos são ultra-significados pela imprensa. Isso quer dizer que, além do significado apreendido ao primeiro contato, outros significados se impõem para gerar uma nova significação - a ultrasignificação - em que valores ocultos, velados, revestem e dão "naturalidade" ao que, na verdade, é um fato histórico. Dizia ele, que a imprensa semanal havia se transformado no centro de uma verdadeira magistratura, "como uma moral moderna, não emancipada, mas garantida pela ciência e para a qual a opinião do especialista é mais requerida do que a do sábio universal" (BARTHES, 2010, p. 127). Essa é a marca do discurso jornalístico que simula falar ao leitor comum, em um sentido primeiro,"traduzindo"temas complexos ao público heterogêneo e não especializado, mas que, ao delegar vozes à "especialistas" revestidos pelo status de "profundos conhecedores", estabelece uma significação própria (ultra-significada), em um discurso que simula o distanciamento pela instauração de uma terceira pessoa, ampliando a crença de verdade no fato enunciado. $\mathrm{O}$ entendimento de Barthes, quando investigava as mitologias contemporâneas, foi de que esse é "um jornalismo totalmente voltado para a democracia", (BARTHES, 2010, p. 127), pois simula a participação de todos no âmbito dos debates e das decisões. Encontra-se aqui, um ponto de diálogo com e a noção de McLuhan (1998) sobre a imprensa em mosaico como um instrumento necessário a um sistema democrático.

A percepção do semiologista sugere pistas que estão presentes, não apenas nos meios impressos originalmente investigados, dentro de uma periodicidade original, mas que podem, agora, ser detectadasnos ambientes virtuais, com atualizações constantes, anunciandoa possibilidade de aplicar o conceito de ultra-significação também nesse formato. A disposição dos temas, dentro do mosaico virtual, a rapidez com que se esvai da página, a alteração do tempo enaltecendo a efemeridade das notícias, são elementos que estabelecem uma segunda significação.

O mosaico é uma estruturapreenchida pelos fatos escolhidos, dentre tantos, para serem enunciados de uma determinada maneira, ou seja, denota a capacidade da imprensa de ter acesso 
aos saberes (notícias) revestir-se do poder de compreendê-los e torná-los fatos com grau de importância que será determinado também pela posição em que vai ser encaixado no mosaico. Por isso, apresentar a informação (não apenas produzi-la) é criar outra significação, gerada dentro da estrutura do mosaico que, como a forma organizadora dos jornais, determina o nível de importância que um tema terá em relação a si próprio e aos outros que competem pelo interesse do leitor. Em meio a essa trama, estão também os elementos da ficção e dos assuntos espetaculares, que têm um segundo significado, ao esfumaçar as fronteiras entre o real e o ficcional, dividindo o mesmo espaço e acessibilidade, tão recorrentes na atual dimensão dos portais de conteúdo jornalístico.

Outra importante contribuição de Barthes para a compreensão das estruturas que fecham os sentidos nos discursos jornalísticos veio por um estudo no qual se debruçou, nos idos dos anos de 1960, investigando a estrutura dos "fait divers". Embora o conceito de "fait divers" tenha sido criado na França, por volta de 1830, marcando o início do jornalismo de massa, que estampava notícias com tratamento folhetinesco (chamadas, então, de fatos diversos), foi o olhar cuidadoso e aguçado do semiólogo, que identificou uma recorrência estrutural, algo quetraçava um sentido encerrado em si mesmo: "uma informação total, ou mais exatamente, imanente; ele contém em si todo o seu saber: não é necessário conhecer nada do mundo para consumir um "fait divers"; ele não remete a nada mais, além dele mesmo" (BARTHES, 1966, p. 196).

Barthes percebeu que sempre havia notícias que tinham um sentido espantoso, absurdo, quase deslocado do meio em que aparecia, ao lado de temas políticos, econômicos e internacionais, esses sim, que exigiam do leitor um conhecimento prévio do mundo. Nos outros casos, classificados como"fait divers" pelo tratamento folhetinesco que recebe, nenhum conhecimento do mundo é exigido e os fatos do dia a dia assumem aspectos dramatizados. Desde as origens do jornal, histórias e romances são preparados para serem lidos em capítulos que seguem a própria periodicidade do jornal, atrelando a ficção e a realidade, em um desenrolar que acompanha o veículo, conforme demonstrado por Meyer (2005). A ideia original de "fait divers" é a de uma abordagem romanceada, dramatizada para os fatos cotidianos. Não são acontecimentos bizarros apenas, mas qualquer tipo de ocorrência que venha a receber um tratamento ficcional pode ser lido como um "fait divers". Além da imanência, outra marca distintiva é a recorrência dos temas, ou seja, são por natureza, repetitivos. O leitor é sempre tomado de estranhamento quando está diante de um "fait divers", porque relações particularizadas entre aspectos distintos entre si assumem desfechos espantosos no decorrer da notícia. Barthes trouxe exemplos pontuais desse sentido fechado: uma mulher esfaqueou o amante: crime passional? Não, para ele não entrar na política. Uma jovem 
criada rapta o bebê de seus patrões: para o resgate? Não, porque ela amava a criança. Segundo o semiólogo, esses são momentos em que o ocorrido é pior do que a causa, pois a agressão, o crime passional e a chantagem seriam práticas perversas de longa história, mas as razões apresentadas, como diferenças políticas ou excesso de carinho, são motivações ridículas que quebram a relação causal entre o fato e a intencionalidade, gerando uma visão impressionante da situação. Os temas ordinários das manchetes são enquadrados nesse tipo de estrutura com tanta "naturalidade" que os tornam parte de qualquer "vida real".

\section{A disposição dos elementos da notícia em sistemas de jornalismo on-line}

A influência que o campo jornalístico exerce sobre os campos de produção cultural, mesmo os mais autônomos, foi objeto de estudo de Pierre Bourdieu (1997). Em um ensaio, o autor mostra que tal campo impõe um conjunto de efeitos que estão ligados à estrutura própria do jornalismo e de sua relação com outras forças externas, como o mercado e os leitores:

\footnotetext{
O campo jornalístico constituiu-se como tal, no século XIX, em torno da oposição entre os jornais que ofereciam antes de tudo 'notícias', de preferência 'sensacionais' (...) e jornais que propunham análises e comentários, aplicados em marcar sua distinção com relação aos primeiros afirmando abertamente valores de objetividade; ele é o lugar de uma oposição entre duas lógicas e dois princípios de legitimação: o reconhecimento pelos pares, concedido aos que reconhecem mais completamente os valores ou os princípios internos, e o reconhecimento pela maioria, materializado no número de receitas, de leitores, de ouvintes ou de espectadores, portanto, na cifra da venda e no lucro em dinheiro, sendo a sanção do plebiscito, nesse caso inseparavelmente um veredicto do mercado. (BOURDIEU, 1997, p. 85).
}

Com o crescimento das mídias, a sociedade permanece investindo o jornalismo de poder, ao mesmo tempo em que o envolve em severas críticas, tal qual demonstra a abordagem de Bourdieu. A reconstrução conceitual das práticas jornalísticas com o advento dos ambientes virtuais, introduz novos sistemas, com uma interface composta por um conjunto de manchetes relacionadas entre si, mais uma vez constituindoum mosaico, formando um todo que poderá até dispensar a visita do leitor ao conteúdo completo de sua matéria, no interior dos hipertextos. Como um sistema aberto, tais portais trocam informações com os leitores e também com os demais sítios de notícias, o que por vezes faz com que vários deles sejam muito parecidos ao nuclear os mesmos assuntos, desprezando a singularidade e a disponibilidade de espaço e tempo que a internet proporciona à prática jornalística. 
O sucesso desses meios também está vinculado à capacidade de estabelecer relações e conexões entre os assuntos dispostos nesse mosaico de notícias nucleadas em assuntos chaves (como política, economia, esportes), "fait divers" e entretenimento (folhetins, ficção). O tempo, no caso do jornalismo on-line, é um grande fator de conectividade, pois são as marcas que distinguem os assuntos muito recentes, mais antigos ou intermediários, compartilhando o mesmo espaço midiático. Esse tempo elementar está marcado ao lado das manchetes, no campo mais nobre do enunciado. Tal demarcação é também um elemento verbo-visual que atua como um identificador materializado de sua presença. Porém, tais signos não denotam, necessariamente, o tempo como um signo da realidade, mas simulam esse tempo, constituindo-o em um significante próprio que é o espaço jornalístico e, nesse caso, especificamente, o espaço virtual, no qual se inscreve o jornalismo on-line.

Também é nesse ambiente simulado que alguns parâmetros críticos se instalam na forma de notícias assombrosas, o que poderia gerar a destruição desse sistema, porque, de certa forma, rompem o equilíbrio do mosaico, caracterizando-se como desestabilizadoras do processo. Para que o sistema se reequilibre, é preciso que outras notícias sejam atenuantes no mesmo espaço fragmentado e compartilhado. Por exemplo, se há uma notícia de desastres naturais, com milhares de mortos ou forte ameaça à economia local, no mesmo espaço, ao lado, outras notícias sobre criação dos filhos, beleza feminina ou futebol, compartilham o campo sistêmico com absoluta "naturalidade". É possível entender que essa é uma forma de recriar a estabilidade desse sistema em particular, o que por si, acaba por refletir o campo social que espelha, já que a imprensa é um sistema que emite perturbação no ambiente.

Como explica Steven Johnson (2003), desde a primeira análise sobre a era da televisão em 1961, o mundo da mídia jornalística mudou muito:

\begin{abstract}
Essas mudanças promoveram um aumento de transmissões entre os canais dos meios de comunicação: hoje há muito mais agentes no sistema (websites, semanários, manchetes nos pagers, redes de notícias vinte e quatro horas por dia), e muito mais reformulações de material jornalístico, ao lado de uma alarmante disposição de soltar, sem crítica, notícias de outra fonte de informação. (...) Em outras palavras, o sistema como um todo deu uma guinada impressionante na direção das redes distribuídas e afastando-se das hierarquias tradicionais topdown. E quanto mais a mídia contempla sua própria imagem, mais provável é que o sistema comece a realimentar a si mesmo, como uma guitarra Stratocaster inclinando-se sobre a amperagem na qual está ligada. (JOHNSON, 2003, p. 99).
\end{abstract}

Para o autor, o resultado final disso é que não há nenhuma história importante na qual a mídia não desempenhe um papel essencial, destacando o talento que possui para criar a própria 
história. Embora haja uma inegável participação social nos portais de conteúdo jornalístico, como a opinião dos leitores on-line, vídeo repórteres e outras intervenções coletivas na construção da notícia, ainda parece resguardado aos editores, o papel do "gatekeeper" (MITCHELSTEIN e BOCZKOWSKI, 2009, p. 63), de acordo com o qual são os jornalistas que decidem o que é ou não notícia. Desse ponto de vista, muito mais do que a interferência dos internautas o que poderia sugerir uma organização emergente do meio social, como tendência de um sistema "bottom-up" algo que surge na base e vai se estendendo ao meio, o que se tem é a manutenção de um sistema "top-down" (de cima para baixo) em que a organização não segue regras próprias dos elementos envolvidos, mas sim uma liderança pré-estabelecida.

\section{Considerações finais}

Os portais de notícias formam um sistema em que campos aparentemente antagônicos estão dispostos, formando, com sua junção, um significado fechado. Um mesmo espaço, simbólico, que simula a passagem do tempo pela marcação das datas, joga com o passado, ao trazer em meio a suas telas, a continuidade dos capítulos de novelas (folhetim), os desdobramentos dos "reality shows", matérias sobre a vida das celebridades, entre outros assuntos que estão suspensos na categoria do tempo. Também é nesse espaço que são reforçados estereótipos, com mulheres seminuas, torcidas de times de futebol e outros campos que destacam notícias bizarras, com especial destaque àquelas com temas policiais. Em um primeiro olhar, é possível captar os assuntos do dia. Nesse mosaico, mesmo as notícias folhetinescas participam da roda de atualização, na forma dos capítulos e das “novidades" que estão ali enunciadas. O folhetim da atualidade pode ser lido ou assistido, já que alguns trechos estão disponíveis para o internauta. Neste caso, há a instalação de um signo verbovisual dos folhetins, em fragmentos de textos e vídeos que compõem o entretenimento do leitor de notícias.

Os "fait divers", notícias de estrutura fechada, cujo sentido encerra-se em si mesmo, segundo a investigação realizada por Roland Barthes e os elementos ficcionais presentes nos portais de notícias poderiam simular um sistema próprio, em sua significação? Em essência, os "fait divers" não exigem conhecimentos prévios do mundo ou do contexto para sua compreensão. Em geral são relativos às paixões humanas ou fenômenos da natureza, para serem compreendidos por qualquer pessoa, pois seu sentido imanente é o que o impulsiona. Tais manchetes espantam por sua aparente desconexão dentre os demais elementos desse sistema, então, apesar de possuírem um sentido fechado, mostram-se como um sistema aberto, pois é na troca de informações com o meio externo,

Comun \& Info, v. 16, n. 2, p. 136-148, jul./dez. 2013 
representado pelo leitor, que desestabilizam o campo simbólico, já que espantar pode significar afastar, por isso, é essencialserem entrelaçados a outros elementos harmônicos que restabeleçam a manutenção do sistema, ajuste esse, que é atingido no desenho do mosaico. Pode-se dizer que outros elementos com maior capacidade de destruição (notícias sobre tragédias, acidentes, políticas ditatoriais etc), são atenuados pelos "fait divers", devido aoalívio da tensão proporcionada pelos conteúdos fenomenais.

Os estudos aproximam de forma inequívoca o jornalismo impresso, ao longo de sua história, do jornalismo on-line, apesar das novas práticas culturais que vem instalando. O princípio do mosaico tem sido o parâmetro de organização cotidiana dos portais noticiosos, bem como a nucleação de notícias e a recorrência dos assuntos, gerando novos campos de significação. O estabelecimento do espaço em que todos os fragmentos de assuntos compartilham a mesma interface, induzindo a uma leitura naturalizada de elementos tão opostos entre si, ou seja,que vão de fortes impactos sociais a curiosos "fait divers", surge como uma manufatura preservada na trajetória histórica de transposição entre os meios.

Esse recurso sugere que a instalação de significantes como "fait divers" e folhetins nos portais de notícias resignificam o próprio conteúdo enunciado, pois são atenuantes da opinião pública, funcionam como neutralizadores em meio aos fragmentos cotidianos. Mergulhados em um caos noticioso, esses significantes são como ilhas, onde se pode escapar da angústia da leitura, apenas baixando o olhar e deixando-se levar por amenidades ou pelos folhetins que agora se fazem presentes na convergência dos comentários sobre os capítulos de novelas ou programas de "reality shows".

Isso não diferencia o jornalismo on-line dos primórdios do jornalismo de massa, iniciado na França, nos anos de 1830. A trama cotidiana ainda permanece como um tecido formado pelo espaço trançado entre realidade e ficção, costurado pelas linhas do tempo,no qual os avanços tecnológicos podem ser relegados ao plano do suporte, porque o jornalismo, mesmo considerado imponderado, em sua ancoragem na internet, dá ares de apenas simular novos recursos, pois para um olhar mais aguçado ressurge como a mesma roupagem daquele praticado há mais de 200 anos. A manutenção do campo simbólico como uma luta pelo poder é travada, diuturnamente, nos mosaicos impressos e on-line, por isso, dominar a arte do mosaico é dominar a própria arte da imprensa, com seus significantes colocados estrategicamente como ladrilhos que dão identidade e fecham o sentido, não importando em qual dos suportes o jornalismo se estabeleça.

Artigo submetido em 22/10/2013 e aceito em 24/02/2014. 


\section{Referências}

BARTHES, R. Mitologias. Tradução de Rita Buongermino, Pedro de Souza e Rejane Janowitzer. São Paulo: Difel, 2003.

BARTHES, R. Essais critiques: structure du fait divers. Paris: Seuil, 1964.

BILL, K.; ROSENSTIEL, T. Os elementos do jornalismo: o que os jornalistas devem saber e o público exigir. Tradução de Wladir Dupont. São Paulo: Geração editorial, 2003.

BOURDIEU, P. Sobre a televisão. Tradução de Maria Lucia Machado. Rio de Janeiro: Jorge Zahar, 1997.

JOHNSON, S. Emergência. Tradução de Maria Carmelita Pádua Dias. Rio de Janeiro: Jorge Zahar, 2003.

KUCINSKI, B. Jornalismo na era virtual: ensaios sobre o colapso da razão ética. São Paulo: Fundação Perseu Abramo, 2004.

McLUHAN, M. Os meios de comunicação como extensões do homem: understanding media. Tradução de Décio Pignatari. São Paulo: Cultrix, 1998.

MEYER, M. Folhetim: uma história. 2. ed. São Paulo: Companhia das Letras, 2005.

MITCHELSTEIN, E.; BOCZKOWSKI, P. J. Between tradition and change: a review of recent research on online news production. Journalism: theory, practice \& criticism, Pennsylvania, v. 10, p. 562-586, Oct. 2009.

RAMONET, I. A explosão do jornalismo: das mídias de massa à massa de mídias. Tradução de D. Estevam. São Paulo: Publisher, 2012.

TÜRCKE, C. Sociedade excitada: filosofia da sensação. Tradução de Antonio A. S. Zuin, et al. Campinas/SP: Unicamp, 2011. 